\title{
Adsorption of sodium hexanoate on $\alpha$-alumina
}

\author{
Seung Yeon Lee ${ }^{\mathrm{a}}$, Rebecca Welbourn ${ }^{\mathrm{a}}$, Stuart M. Clarke ${ }^{\mathrm{a}, *}$, Maximilian W.A. Skoda $^{\mathrm{b}}$, Luke Clifton ${ }^{\mathrm{b}}$, \\ Ali Zarbakhsh ${ }^{\mathrm{c}}$
}

${ }^{a}$ BP Institute and Department of Chemistry, University of Cambridge, Madingley Rise, Madingley Road, Cambridge, UK

${ }^{\mathrm{b}}$ ISIS, Rutherford Appleton Laboratory, Harwell Science and Innovation Campus, Didcot, UK

'School of Biological and Chemical Science, Queen Mary, University of London, Joseph Priestley Building, Mild End Road, London, UK

\section{A R T I C L E I N F O}

\section{Article history:}

Received 2 April 2013

Accepted 11 June 2013

Available online $\mathrm{xxxx}$

\section{Keywords:}

Adsorption

Sodium hexanoate

Aluminium oxide

Ligand exchange

Neutron reflection

\begin{abstract}
A B S T R A C T
Neutron reflection and adsorption isotherm measurements have been used to study the adsorption behaviour of hexanoic acid onto $\alpha$-alumina surfaces. Importantly, the $\mathrm{pH}$ dependence of the behaviour has been characterised with a pronounced maximum in adsorption identified at a $\mathrm{pH}$ of approximately 5 , close to the $\mathrm{p} K_{\mathrm{a}}$ of the acid. The adsorbed layer is identified as a bilayer, which is reasonable given the hydrophilic nature of both side of the layer, and has a thickness of $13 \AA$, suggesting significant extent of interdigitation. At $\mathrm{pH} 5$, the layer has much lower extent of hydration relative to the higher $\mathrm{pH}$ of 7 , consistent with the increased total adsorption at $\mathrm{pH}$ 5. A number of different mechanisms for the binding of the hexanoic acid to the surface are considered. The experimental data, combined with calculations using equilibrium/binding constants of the surface and ligands, indicates that a ligand exchange reaction may be the most significant mechanism.
\end{abstract}

(c) 2013 Elsevier Inc. All rights reserved.

\section{Introduction}

Understanding the adsorption of surfactants and other species from solution to solid surfaces is crucial in many academic and industrial applications from detergency to lubrication. This is particularly so in the case of aluminium oxide due to the industrial importance in areas such as engineering, ceramics, paints and plastics among others. Importantly, alumina surface sites are also excellent models of particular active sites of clay minerals. An important part of the behaviour is the variation with $\mathrm{pH}$. It is found that many minerals are positively charged at low $\mathrm{pH}$ but progress through an iso-electric point to negative charges at high $\mathrm{pH}$, due to proton exchange at the mineral surface. It has been found that different surface sites have different dissociation/association constants and hence different $\mathrm{pH}$ dependence. The iso-electric point (I.E.P.) of alumina surface is variously reported to be 5.0-9.0 and varies depending on its crystal phase and geometry [1-8].

Ionisable functional groups such as a carboxylate within an organic species are capable of dissociation or association depending on the $\mathrm{pH}$ of the solution and the dissociation constant, $K_{\mathrm{a}}$ (often expressed as $-\log _{10}\left(K_{\mathrm{a}}\right)$ or $\left.\mathrm{p} K_{\mathrm{a}}\right)$ of the group. This ionisation is a key factor determining the adsorption onto oxide surfaces. In addition there are a number of methods by which organic species might bind to a surface including electrostatic, hydrogen bonding and ligand exchange, as discussed below.

* Corresponding author. Address: BP Institute, Bullard Laboratories, Madingley Road, Cambridge CB3 OEZ, UK. Fax: +44 1223765701.

E-mail address: stuart@bpi.cam.ac.uk (S.M. Clarke).
In this work the adsorption of the anionic carboxylate, sodium hexanoate, illustrated in Fig. 1, onto the surface of $\alpha$-alumina in both powder and single crystal (sapphire) forms is presented. The hexanoic acid is most convenient as the longest alkyl chain carboxylic acid that still has a reasonable solubility in water. The long alkyl chain is helpful in the neutron experiments giving enhanced reflection relative to a shorter homologue. As outlined above the surface of the oxide has a number of $\mathrm{Al}-\mathrm{OH}$ groups that give rise to a $\mathrm{pH}$ dependent surface charge. The I.E.P. of $\alpha$-alumina in a (0001) single crystal form $\left(\mathrm{pH}_{\mathrm{IEP}}=5-6\right)$ is reported to be more acidic than that in powder form $\left(\mathrm{pH}_{\mathrm{IEP}}=8-9\right)$ due to the dominance of $\equiv \mathrm{Al}_{2} \mathrm{OH}$ surface groups on the single crystal with a different $\mathrm{pK}$ values [1-8]. The adsorbate, hexanoic acid, has a $\mathrm{p} K_{\mathrm{a}}$ of 4.9 [9]. Hence over most of the accessible $\mathrm{pH}$ range in water, both alumina and hexanoic acid are expected to exhibit significant $\mathrm{pH}$ variation which might be expected to lead to significant changes in adsorption behaviour with some differences between powder and single crystal forms.

\subsection{Adsorption isotherm}

An adsorption isotherm relates the concentration of adsorbate at the interface to its equilibrium concentration in the liquid phase. This adsorption behaviour is often interpreted using the Langmuir isotherm [10-13]:

$\Gamma_{1}=\frac{\Gamma_{\mathrm{ML}} K_{\mathrm{L}} C_{1}}{K_{\mathrm{L}} C_{1}+1}$ 


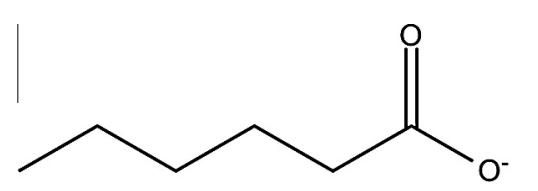

Fig. 1. Sodium hexanoate (2-column fitting).

where $C_{1}$ is the concentration of component 1 at equilibrium in the liquid phase, $\Gamma_{1}$ is the surface excess of the component $1, \Gamma_{\mathrm{ML}}$ is the surface concentration adsorbed at monolayer coverage, and $K_{\mathrm{L}}$ is the Langmuir equilibrium constant, related to the enthalpy of adsorption. The conditions for this type of Langmuir adsorption are that the adsorbent is homogeneous, both solute and solvent have equal surface areas, both surface and bulk phases exhibit ideal behaviour and the adsorption is limited to monolayer coverage $[10,11,13]$.

Lateral interaction between alkyl chains is not uncommon with surfactant adsorption and leads to the initial slope of the isotherm becoming S-shaped. This S-shaped isotherm can be represented by $[10,14,15]$ :

$\Gamma_{1}=\frac{\Gamma_{\mathrm{ML}} K_{\mathrm{S}} C_{1}^{n}}{K_{\mathrm{S}} C_{1}^{n}+1}$

This model is similar to the Langmuir theory but with an aggregation number, $n$, and a different equilibrium constant, $K_{\mathrm{S}}$. This Sshaped behaviour has been reported for adsorption on alumina surfaces [16-20]. If surface aggregation occurs then $n$ should be greater than 1 .

\subsection{Neutron reflection}

Neutron reflectivity has now been well established as an important depth profiling tool for resolving structural conformation of complex systems perpendicular to an interface on an Angstrom length scale [21-23]. In a typical neutron reflectivity experiment a highly collimated neutron beam is reflected from an interface. The intensity of the specular reflection is then measured as a function of momentum transfer perpendicular to the interface, $Q$ which is defined by the beam incident angle, $\theta$ and the neutron wavelength, $\lambda$ :

$Q=\frac{4 \pi \sin \theta}{\lambda}$

The reflected intensity is related to the refractive index profile normal to the interface. The neutron reflective index $(n)$ of nonabsorbing materials can be defined as:

$n=1-\frac{\lambda^{2} \rho}{2 \pi}$

where $\rho$ is the scattering length density (SLD) of the material and defined by

$\rho=\frac{\sum b_{\mathrm{coh}}}{v_{\mathrm{M}}}$

where $v_{\mathrm{M}}$ is the molecular volume and $b_{\text {coh }}$ is the coherent scattering length of all atoms in the molecules. Importantly the scattering length varies across the periodic table and between isotopes, most significantly hydrogen (H) and deuterium (D). Values of $\rho$, of interest here are given in Table 1.

The scattering length density of a layer $\rho$ can be written in terms of contributions from the adsorbed species $\rho_{1}$ and the bulk phase $\rho_{2}$, and is related to the volume fraction of each component at the surface:

$\rho=\rho_{1} \varphi_{1}+\rho_{2} \varphi_{2}$
Table 1

Scattering length density of selected compounds.

\begin{tabular}{llr}
\hline Material & Formula & $\rho / 10^{-6}\left(\AA^{-2}\right)$ \\
\hline Sapphire & $\mathrm{Al}_{2} \mathrm{O}_{3}$ & 5.75 \\
Heavy water & $\mathrm{D}_{2} \mathrm{O}$ & 6.33 \\
Water & $\mathrm{H}_{2} \mathrm{O}$ & -0.56 \\
$50 \% \mathrm{D}_{2} \mathrm{O}$ & $\mathrm{HDO}$ & 2.89 \\
Sodium hexanoate & $\mathrm{C}_{6} \mathrm{H}_{11} \mathrm{O}_{2} \mathrm{Na}$ & 0.59 \\
\hline
\end{tabular}

where $\varphi_{1}$ and $\varphi_{2}$ are their volume fractions and the sum of the volume fractions must be unity (i.e. $\varphi_{1}+\varphi_{2}=1$ ). This technique benefits from the fact that neutrons are scattered differently by hydrogen $(\mathrm{H})$ and deuterium (D) nuclei. This contrast variation is normally achieved either by selective deuteration of the molecules of interest or by using an appropriate mixture of $\mathrm{H}$ and $\mathrm{D}$ solvent (i.e. $\mathrm{H}_{2} \mathrm{O}$ and $\mathrm{D}_{2} \mathrm{O}$ ) to match the scattering from a particular part of the structure.

Experimental neutron reflectivity profiles were analysed using RasCAL (version Beta 1, A. Hughes, ISIS Neutron Source, Rutherford Appleton Laboratory). This uses an optical matrix formalism based on the Abeles approach [24,25]. In this approach the interface is described as a series of layers and each of them is characterised by its SLD, thickness and roughness. A least squares minimisation is used to reduce the differences between modelled and experimental data. The simplest possible model, which adequately described the data, was selected. Neutron reflection profiles were obtained under different isotopic conditions and were constrained to fit to the same structure (layer composition and thickness profile) with SLD varied between data-sets from different contrasts as required.

\section{Experimental}

$\alpha$-Alumina powder was supplied by Absco Materials (manufacturer's technical data: surface area $=26 \pm 1 \mathrm{~m}^{2} / \mathrm{g}$, particle size $=2 \mu \mathrm{m} \mathrm{d} 90,0.4 \mu \mathrm{m} \mathrm{d} 50$ and $0.2 \mu \mathrm{m} \mathrm{d} 10$, chemical purity of $>99.99 \%$ ). Sapphire wafers (50 mm diameter, $5 \mathrm{~mm}$ thick, (0001) C-plane, single side polished) were obtained from PI-KEM Ltd. and cleaned as described below. Sodium hexanoate (99-100\% purity) was purchased from Sigma Aldrich and used as received.

The $\alpha$-alumina powders were characterised by elemental analysis and BET surface area measurement (Micromeritics Tristar 3000, in the Department of Material Science \& Metallurgy at the University of Cambridge) and Xray-Powder diffraction (X-Pert MPD Powder X-ray Diffractometer, in the Department of Earth Science at the University of Cambridge) before use. TOC instrument (Sievers InnovOX, Laboratory TOC Analyser, GE Power \& Water, in the BP Institute, at the University of Cambridge) was used for the isotherm study. Orthophosphoric acid ( $45 \mathrm{wt} \%$ in water) was used to remove inorganic carbons and sodium persulfate as oxidizer supplied by GE Analytical instruments Ltd.

The adsorption isotherm of sodium hexanoate was determined by the solution depletion method, where the change in adsorbate concentration (depletion) after contact with powdered solids is measured. Known amounts of sodium hexanoate and $\alpha$-alumina powder were added into $40 \mathrm{ml}$ of $3 \mathrm{mM} \mathrm{NaCl}(\mathrm{aq})$ in a centrifuge tube. The mixture was left for at least $24 \mathrm{~h}$ on a mixing tumbler at room temperature to allow for equilibrium. The $\mathrm{pH}$ of the solution was monitored and altered if necessary to maintain the desired value. Hydrochloric acid ( $\mathrm{HCl}$, Sigma Aldrich) and sodium hydroxide ( $\mathrm{NaOH}$, Sigma Aldrich) were used to adjust the $\mathrm{pH}$ of the samples. The mixture then was centrifuged at $10,000 \mathrm{~g}$ for 30 min to separate the solids. The total amount of organic carbon in the supernatant was measured by the TOC analyser. Some 


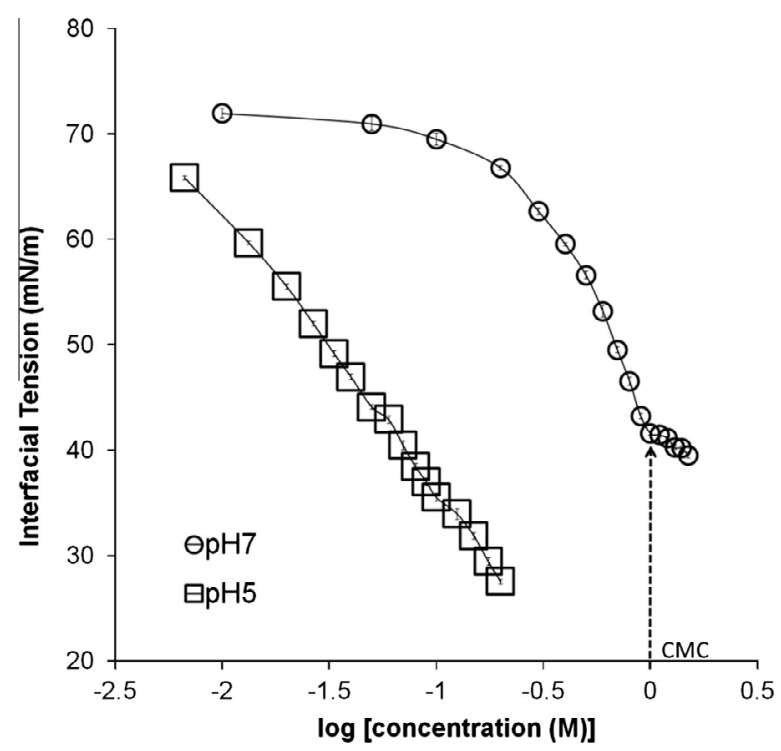

Fig. 2. Interfacial tension of sodium hexanoate at $\mathrm{pH} 5$ and 7 as a function of concentration. At $\mathrm{pH} \mathrm{7,} \mathrm{the} \mathrm{CMC} \mathrm{of} \mathrm{the} \mathrm{carboxylate} \mathrm{is} \mathrm{approximately} 1 \mathrm{M}$. At $\mathrm{pH} 5$, the low solubility of sodium hexanoate prevents the observation of the CMC (2column fitting).

supernatants required dilution to bring them into the required concentration range of the TOC device.

The new sapphire wafers for neutron reflection were cleaned by mild piranha with a concentration of $5: 4: 1$ of $\mathrm{H}_{2} \mathrm{O}$, concentrated sulphuric acid, and $30 \% \mathrm{H}_{2} \mathrm{O}_{2}$ at temperature of $80^{\circ} \mathrm{C}$ for $15 \mathrm{~min}$, followed by extensive rinsing with ultra-pure water. The wafers were exposed to UV-ozone for $30 \mathrm{~min}$. All plastic bottles, other parts of the cell and connecting tubing were cleaned with Decon 90 followed by extensive rinsing with ultra-pure water. Glassware was avoided to minimise any contamination of silicon ions on the alumina substrates [3].

The sapphire wafer was clamped against a PTFE trough to make a solid/liquid cell by means of a steel assembly. Solutions were prepared and injected into in the cell manually with plastic syringes. The solutions were injected and drawn out several times to ensure effective exchange.

The neutron reflection measurements were made on INTER at ISIS, Rutherford Appleton Laboratory [26,27]. The instrument uses a spallation target neutron source and determines the wavelength of the neutrons (lambda 1-15 $\AA$ ) by time of flight to the detector. The solid/liquid interface is horizontal and the incident beam is projected down onto the surface and then reflected up. A single detector is used at particular reflection angles and combined with the wavelength to calculate the accessible range of the momentum transfer, $Q$ [26]. The reflected signal is normalised by separate transmission measurements straight through the sapphire wafer without reflection. The beam resolution $(\Delta Q / Q)$ on INTER was $4 \%$. The beam resolution is predominately affected by slit settings and it causes smearing out of features in the reflectivity curve such as the critical edge or fringes. The data were analysed using the software, RasCAL [28].

This solid-liquid cell was mounted on a sample changer on the instrument which was attached to accurate goniometers used to align the sample. Samples were accurately aligned with respect to both angles of incident and reflection (over a range of $0.2^{\circ}$ ), and position (over $1 \mathrm{~mm}$ height range) to optimise the reflected signal. The measurements were all made at room temperature $\left(\sim 20^{\circ} \mathrm{C}\right)$. The substrates were initially characterised with three contrasts of water $\left(\mathrm{H}_{2} \mathrm{O}, \mathrm{D}_{2} \mathrm{O}, 50 \% \mathrm{D}_{2} \mathrm{O}\right)$ before exposure to the surfactant solutions.

\section{Results}

The $\alpha$-alumina powder was initially characterised by elemental analysis and the carbon content in the powder was found to be $0.01 \mathrm{wt} \%$. The specific surface area was determined by nitrogen adsorption and found to be $26.95 \pm 0.16 \mathrm{~m}^{2} \mathrm{~g}^{-1}$. X-ray diffraction showed that the crystal phase was pure $\alpha$-alumina, in a good agreement with the data provided by the manufacturer.

The surface tension as a function of the amount of sodium hexanoate in water at pH 5 and 7 was measured and is shown in Fig. 2. The data indicates a break point at a concentration of $1 \mathrm{M}[29,30]$ at $\mathrm{pH} 7$ with an interfacial tension of $41.6 \pm 0.5 \mathrm{~m} \mathrm{Nm}^{-1}$ which is relatively similar to other common surfactants. This suggests that this species has a critical micelle concentration, CMC. Fig. 2 also indicates that at pH 5 near its $\mathrm{p} K_{\mathrm{a}}$, there is no evidence of a CMC. We attribute this to the low solubility of sodium hexanoate in water $(\approx 0.2 \mathrm{M})$ although there is a lower interfacial tension compared to $\mathrm{pH} 7$.

\subsection{Adsorption isotherm}

Adsorption isotherms of sodium hexanoate on $\alpha$-alumina powder were measured using a TOC analyser as shown in Fig. 3. The solid lines in Fig. 3 are the comparison with non-Langmuir (Sshaped) isotherm. This S-shaped isotherm was chosen because of its common use for surfactants showing better fits than the Langmuir isotherm. The aggregation numbers $(n)$ resulting from the lateral interaction are all very close to unity (between 1 and 2) and hence we cannot conclude that there is a significant variation. (When $n$ is 1, the isotherm is reduces to the Langmuir equation). The equilibrium constants (Ks) extracted from the S-shaped isotherms are $4.5 \times 10^{3}, 1.78 \times 10^{3}, 1.71 \times 10^{3}$ and $13.8 \mathrm{dm}^{3} \mathrm{~g}^{-1}$ at $\mathrm{pH} 3,5,7$ and 9 respectively. These are relatively small compared to the adsorption of non-ionic surfactant (Triton X-100) on silica gel showing S-shaped isotherm curves with the $n$ and Ks values of 4.0 and $7.25 \times 10^{14} \mathrm{dm}^{3} \mathrm{~g}^{-1}$ according to Gu et al. [15]. Importantly we note that the adsorption of sodium hexanoate on $\alpha$-alumina powder is low at $\mathrm{pH} 3$, rises with $\mathrm{pH} 5$ but then falls again at pH 7 and 9. This pH dependence is now discussed in more detail.

The dependence of the hexanoic acid adsorption was measured across a range of $\mathrm{pH}$ and is illustrated in Fig. 4. This Figure presents

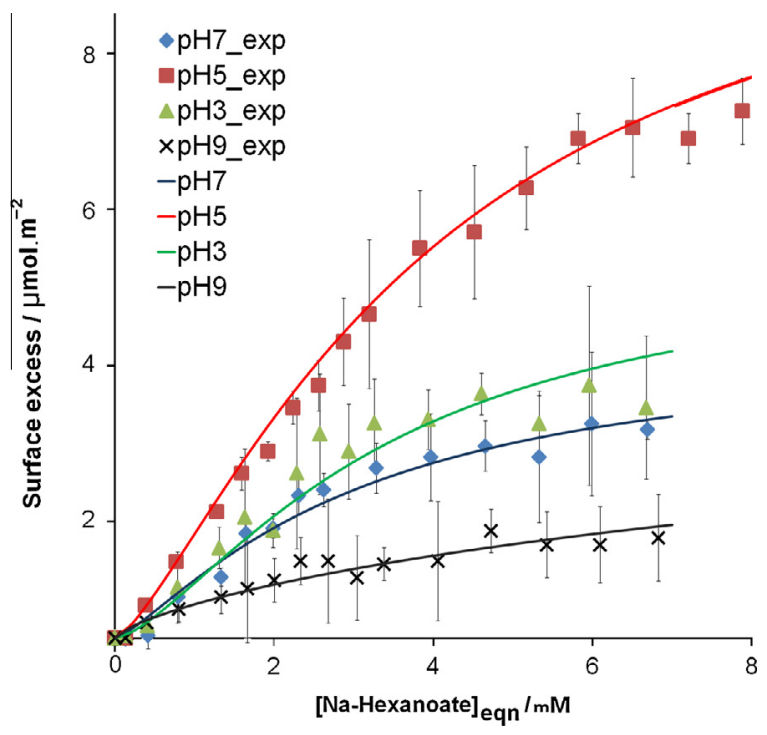

Fig. 3. (a) Adsorption isotherm of sodium hexanoate at $\mathrm{pH} 3,5,7$ and 9 ( $40 \mathrm{ml}$, and $0.11 \mathrm{~g} \alpha$-alumina powder) measured by solution depletion method with nonLangmuir (S-shape) theory. 


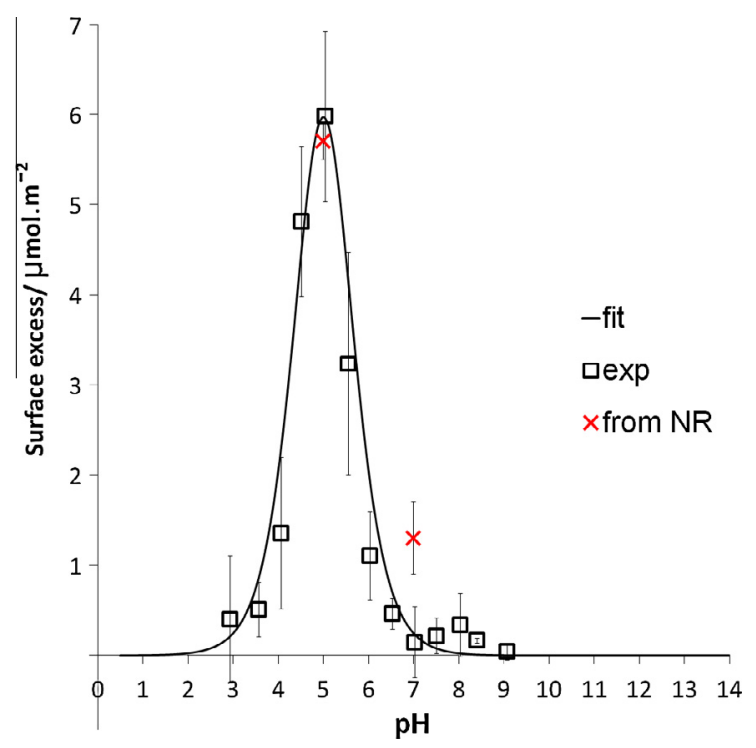

Fig. 4. Surface excess of sodium hexanoate $(6 \mathrm{mM}$ of sodium hexanoate in $40 \mathrm{ml}$ solution with $0.11 \mathrm{~g} \alpha$-alumina) as a function of $\mathrm{pH}$, measured by solution depletion. Fits (solid line) using the equilibrium and binding constants listed in Table 3. Two surface excess values calculated from the neutron data at pH 5 and 7 in Fig. 5 and Table 2, are also included.

the adsorption for a constant hexanoic acid solution concentration of $6 \mathrm{mM}$ at different pHs. This figure clearly illustrates rather minimal adsorption at high and low $\mathrm{pH}$ but a pronounced maximum in the adsorption at $\mathrm{pH}=5$. The ionic strength $(I=3 \mathrm{mM})$ for all isotherms was kept the same.

\subsection{Neutron reflection and the structure of the hexanoic acid adsorbed layer}

The neutron reflectivity of a bare sapphire crystal in three contrasts of $\mathrm{D}_{2} \mathrm{O}, \mathrm{H}_{2} \mathrm{O}$ and $50 \% \mathrm{D}_{2} \mathrm{O}$ are shown in Fig. 5a. The reflec- tivity profiles for all three contrasts were fitted to a single model with the scattering length densities $\rho$ of the sapphire and water contrasts, and a surface roughness. The fits to the data shown by solid lines and the parameters are given in Table 2. Very good agreement was found between the calculated and experimental data, as shown in Fig. 5a. The fitted SLD of $50 \% \mathrm{D}_{2} \mathrm{O}$ was found to be $2.50 \times 10^{-6} \AA^{-2}$, slightly smaller than that expected $\left(2.89 \times 10^{-6} \AA^{-2}\right)$ which we attribute to imperfect exchange of fluids on refilling the trough. A surface roughness of $2 \pm 1 \AA$ was used to fit the data.

Fig. 5b shows the reflectivity from solutions of sodium hexanoate in water adjacent to the sapphire crystal. From careful fitting of this data we can determine the extent of adsorption of sodium hexanoate on the sapphire crystal at pH 5 and 7. The layer was modelled with a single uniform layer of surfactant and the fitted parameters of adsorption determined in this way are given in Table 2. The thickness of hexanoate bilayer is calculated to be $13 \pm 1 \AA$ and $15 \pm 3 \AA$ with a roughness of $3 \pm 1 \AA$ and $2 \pm 1 \AA$ at pH 5 and 7 respectively. The extended chain length of a monolayer of the hexanoic acid is reported to be $\sim 10 \AA$ [31]. Hence we conclude that there is a hexanoic acid bilayer at the surface and the carboxylate tails in the bilayer interdigitate to some significant extent. The formation of a bilayer is reasonable given that both the solid surface and the water will prefer to be in contact with the fatty acid head groups rather than the hydrophobic tails which would be a consequence of a monolayer adsorption.

The fitted structural parameters suggest a reasonably complete fatty acid bilayer adjacent to the solid surface but with $37 \%$ water (by volume) at $\mathrm{pH}$ 5. This water content is not unreasonable given the likely hydration of the acid head groups. However, the total amount adsorbed is much reduced, the layer is much more incomplete and contains rather more water ( $85 \%$ water by volume) at $\mathrm{pH}$ 7. The area per pair of hexanoate molecules in the adsorbed bilayer is approximately $58 \pm 3 \AA^{2}$ at pH 5 and $210 \pm 5 \AA^{2}$ at pH 7. The untilted fatty acid is reported to have the area of approximately $20 \AA^{2}$ per molecule [32]. Hence the hexanoic acid bilayer could be slightly tilted on the surface with some water content. The volume of a sodium hexanoate molecule was conserved and constrained upon fitting, and was estimated to be $237 \AA^{3}$ from its density of $0.97 \mathrm{~g} \mathrm{~cm}^{-3}$ and its molecular weight of $138.2 \mathrm{~g} \mathrm{~mol}^{-1}$. The surface excess of hexanoate is $5.7 \pm 0.2 \mu \mathrm{mol} \mathrm{m}^{-2}$ for $\mathrm{pH} 5$
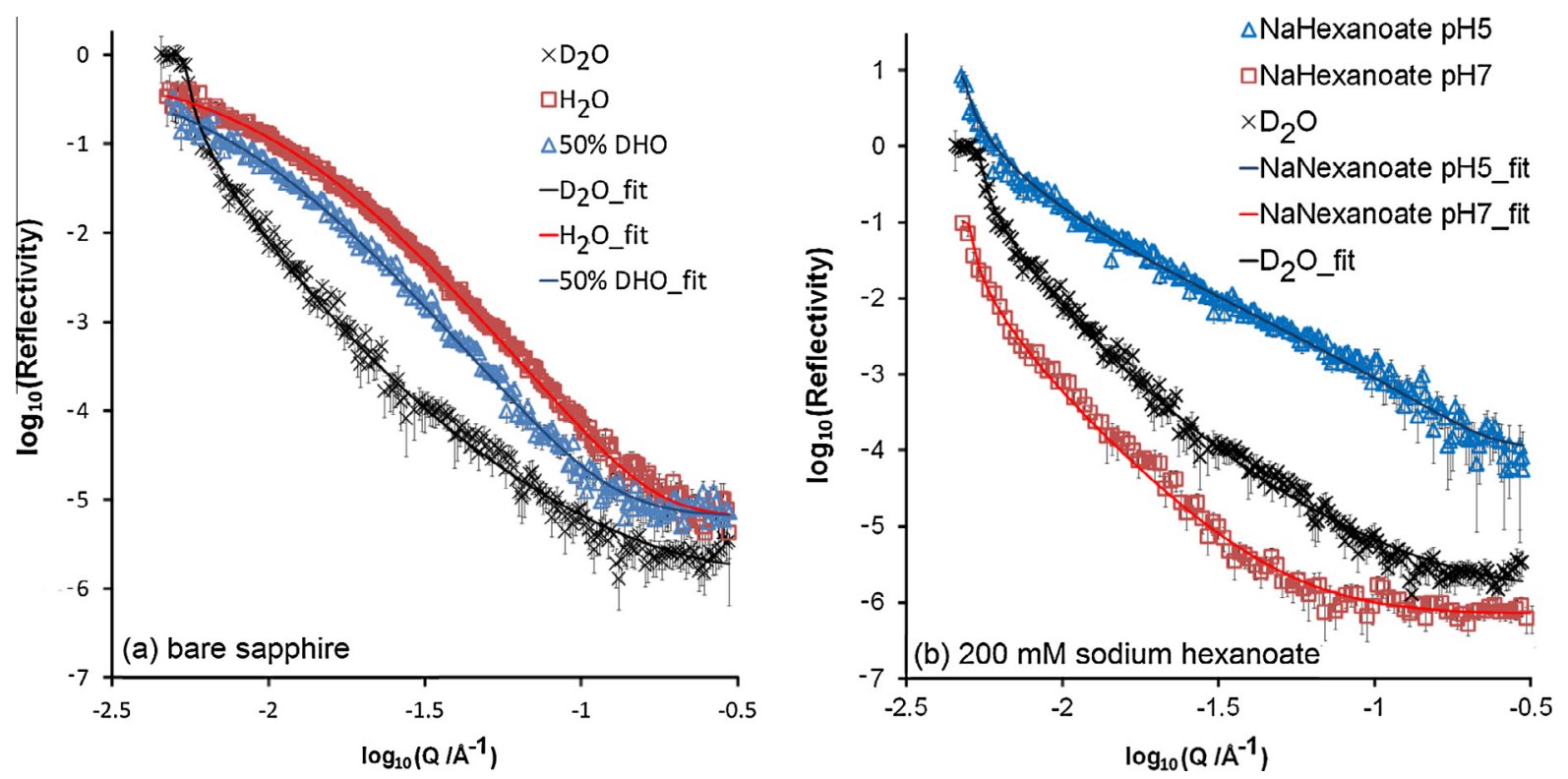

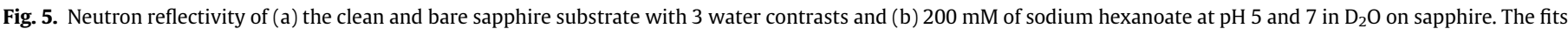
to the data set are shown by the solid lines. Each successive data set in (b) is multiplied by 10 for clarity. 
Table 2

Fitted parameters for the adsorption of sodium hexanoate at pH 5 and 7 determined by neutron reflection.

\begin{tabular}{|c|c|c|c|c|c|c|}
\hline $\mathrm{pH}$ & $\rho \pm 0.1 / 10^{-6}\left(\AA^{-2}\right)$ & Thickness $(\AA)$ & Roughness $(\AA ̊)$ & $\varphi_{\text {water }} \pm 0.05$ & Area per of molecule $\left(\AA^{2}\right)^{a}$ & $\Gamma\left(\mu \mathrm{mol} \mathrm{m}^{-2}\right)$ \\
\hline 5 & 2.7 & $13 \pm 1$ & $3 \pm 1$ & 0.37 & $58 \pm 3$ & $5.7 \pm 0.2$ \\
\hline 7 & 5.4 & $15 \pm 3$ & $2 \pm 1$ & 0.85 & $210 \pm 5$ & $1.5 \pm 0.4$ \\
\hline
\end{tabular}

a This is an area per pair of molecules in the bilayer.

and $1.5 \pm 0.4 \mu \mathrm{mol} \mathrm{m}^{-2}$ for $\mathrm{pH}$ 7. The surface excess calculated from neutron reflectivity is compared with the adsorption determined by depletion isotherm in Fig. 4, and shows very good agreement.

\section{Discussion}

There are a number of potential complexation models that can be considered when trying to understand the observed adsorption behaviour of the hexanoic acid on alumina.

\subsection{Ligand exchange mechanism}

The adsorption isotherms vary very strongly with $\mathrm{pH}$ as shown in Figs. 3 and 4 with a pronounced maximum in adsorption at $\mathrm{pH} 5$. We note that this maximum is near the $\mathrm{p} K_{\mathrm{a}}$ of sodium hexanoate $\left(\mathrm{p} K_{\mathrm{a}}=4.9\right)$. The adsorption behaviour can be modelled using surface exchange equilibria, as discussed above. Here we consider a model based on sodium hexanoate binding by ligand exchange of the surface hydroxyl $(-\mathrm{OH})$ groups (e.g. $>\mathrm{Al}-\mathrm{OH}+{ }^{-} \mathrm{OOC}-\mathrm{R} \leftrightarrow>\mathrm{Al}-$ $\mathrm{OOC}-\mathrm{R}+\mathrm{OH}^{-}$, where $\mathrm{RCO}_{2}^{-}$is the exchanging ligand). This mechanism usually has distinctive $\mathrm{pH}$ behaviour [33]. At the lowest $\mathrm{pH}$ there are rather few ligand anions so adsorption is rather small. As the $\mathrm{p} K_{\mathrm{a}}$ of the ligand is passed the amount of the ligand anion increases and exchange is effective. However, at high $\mathrm{pH}$ the number of $-\mathrm{OH}$ ions dominates competing more effectively for the surface sites $[33,34]$. Hence the hexanoate ligand would be expected to exhibit a maximum in adsorption with $\mathrm{pH}$ near its $\mathrm{p} K_{\mathrm{a}}$ value, as observed.

Calculations using appropriate equilibrium constants, have been used to quantitatively model this surface complexation [35]. Table 3 gives the binding and equilibrium constants used in this case. Other than the ligand exchange binding constant all other constants are available in the literature, so in fitting our data we are in effect determining this equilibrium constant. The calculated pH dependence of the adsorbed amount is displayed in Fig. 4 (solid line). This result shows very reasonable agreement with the experimental data, given the relatively constrained nature of this model. Hence we conclude that the mechanism of the hexanoate adsorption is consistent with 'ligand-exchange'. If this is the case we can also provide an estimate of the ligand exchange equilibrium constant $\left(\mathrm{p} K_{\mathrm{L}}=-0.9\right.$ ), which is comparable to $\mathrm{p} K_{\mathrm{L}}$ values of single inorganic ions on alumina surface (i.e. $\mathrm{AlOH}+\mathrm{PO}_{2}^{3-}+$ $\mathrm{H}^{+} \leftrightarrow \mathrm{AlPO}_{4}^{2-}+\mathrm{H}_{2} \mathrm{O}: \quad \mathrm{p} K_{\mathrm{L}}$ of -13.57 and $\mathrm{AlOH}+\mathrm{SO}_{4}^{2-}+\mathrm{H}^{+} \leftrightarrow$ $\mathrm{AlSO}_{4}^{-}+\mathrm{H}_{2} \mathrm{O}: \mathrm{pK}_{\mathrm{L}}$ of 0.48 ) reported by Karamalidis et al. [35].

\subsection{Hydrogen bonding interactions}

The surface charge of alumina is pH dependent and the carboxylate functional group in sodium hexanoate also has significant $\mathrm{pH}$ behaviour. At low $\mathrm{pH}$, below the $\mathrm{p} K_{\mathrm{a}}$ of hexanoate $\left(\mathrm{p} K_{\mathrm{a}}=4.9\right)$, the hexanoic acid would be a neutral species (protonated carboxylic acid) with positively charged substrate (alumina). Under these conditions one might expect hydrogen bonding to dominate the adsorption behaviour of the hexanoic acid onto surface hydroxyls groups although many of these will be protonated (e.g.
Table 3

Binding and equilibrium constants used for ligand exchange calculation in Fig. 4.

\begin{tabular}{lll}
\hline Equilibrium sites & Equilibrium constant, $K_{\mathrm{i}}$ & Reference \\
\hline $\mathrm{AlOH}_{2}^{+} \leftrightarrow \mathrm{AlOH}+\mathrm{H}^{+}$ & $K_{1}=6.3 \times 10^{-6} \mathrm{~mol} \mathrm{dm}^{-3}$ & {$[36,37]$} \\
$\mathrm{AlOH} \leftrightarrow \mathrm{AlO}^{-}+\mathrm{H}^{+}$ & $K_{2}=2.7 \times 10^{-10} \mathrm{~mol} \mathrm{dm}^{-3}$ & {$[36,37]$} \\
$\mathrm{AlOH}+\mathrm{M}^{+} \leftrightarrow \mathrm{AlOM}^{+} \mathrm{H}^{+}$ & $K_{\mathrm{M}}=4.7 \times 10^{-10}$ & {$[36,37]$} \\
$\mathrm{C}_{6} \mathrm{OOH} \leftrightarrow \mathrm{H}^{+}+\mathrm{C}_{6} \mathrm{OO}^{-}$ & $K_{\mathrm{a}}=1.3 \times 10^{-5} \mathrm{~mol} \mathrm{dm}^{-3}$ & {$[9]$} \\
$\mathrm{AlOH}+\mathrm{C}_{6} \mathrm{OO}^{-} \leftrightarrow \mathrm{AlC}_{6} \mathrm{OO}+\mathrm{OH}^{-}$ & ${ }^{+} K_{\mathrm{L}}=8.0$ & Calculated \\
& & here \\
Total amount of fatty acid & $6.0 \times 10^{-3} \mathrm{~mol} \mathrm{dm}^{-3}$ & Experimental \\
Total monovalent cation $\left(\mathrm{M}^{+}\right)$ & $3.0 \times 10^{-3} \mathrm{~mol} \mathrm{dm}^{-3}$ & Experimental \\
Total number of Al sites & $8.3 \times 10^{-4} \mathrm{~mol} \mathrm{dm}^{-3}$ & {$[36]$}
\end{tabular}

${ }^{+}$Note. Binding constant for ligand exchange was the only unknown parameter for the fitting.

a This is a total concentration of $\mathrm{Al}$ sites in $40 \mathrm{ml}$ suspension with $0.11 \mathrm{~g}$ of $\alpha$ alumina powder.

$\left.\mathrm{Al}-\mathrm{OH}_{2}^{+} \ldots \mathrm{HOOC}-\mathrm{R}\right)$. However, the adsorption at low $\mathrm{pH}$ is very small. Hence we conclude that such hydrogen bonding either does not occur or is not significant. The related behaviour of a protonated fatty acid, carboxylate anion and a cationic ammonium species has been reported in the literature $[38,39]$ in the bulk.

\subsection{Electrostatic interactions}

At intermediate $\mathrm{pH}\left(\mathrm{p} K_{\mathrm{a}}\right.$ of hexanoate $=4.9<\mathrm{pH}<$ I.E.P. of alumina $=5-6$ for single crystals or 8-9 for powders), the carboxylate is negatively charged and the alumina surface positive - hence a strong adsorption (e.g. $\mathrm{Al}-\mathrm{OH}_{2}^{+} \ldots-\mathrm{OOC}-\mathrm{R}$ ) might be expected. At higher $\mathrm{pH}$ (>I.E.P. of alumina), both species will be negatively charged - and one would expect low adsorption. Hence one might expect a maximum in adsorption if electrostatics dominates the interactions. The maximum would be between the $\mathrm{p} K_{\mathrm{a}}$ of the acid and the I.E.P. of the AlOH surface sites. In some respects this agrees with the experimental observations collected by adsorption onto powdered alumina above. On this simple electrostatic binding model, the adsorption might be expected to have a maximum midway between the $\mathrm{p} K_{\mathrm{a}}$ of the acid (4.9) and the I.E.P. of the alumina (8-9 for a powdered substrate) where they have the largest opposite charge. Hence the maximum of adsorption is expected to occur at approximately $\mathrm{pH}$ 6.5-7. However, this is significantly above the value that observed in Fig. 4, where the maximum is at $\mathrm{pH}=5$. This difference may arise from several effects, such as the estimates of I.E.P. and $\mathrm{p} K_{\mathrm{a}}$. Alternatively, we may conclude that electrostatic interactions are not the dominant binding effect.

\subsection{Bridging mechanism}

This mechanism requires the presence of multi-valent ions to hold together two species of the same charge. In our experiments where there are no multi-valent ions and hence it is considered unlikely that cation bridging would be significant. In addition, cation bridging is most likely where the two species have similar charge. This would lead to a maximum in adsorption at high $\mathrm{pH}$ and not, as observed, at intermediate $\mathrm{pH}$ [40]. Even if there might be sufficient amount of aluminium ions dissolved from alumina substrates, the 
maximum in adsorption at high $\mathrm{pH}$ for this mechanism was not observed here.

Other possible origins of adsorption interactions include Van der Waals (VdW) forces. However we do not expect significant $\mathrm{pH}$ dependence behaviour from the VdW. Hence, we conclude that this is not the dominant mechanism for the observations here.

There are a number of works reporting a maximum in the adsorption of anionic carboxylates on alumina at the $\mathrm{pH}$ near the $\mathrm{p} K_{\mathrm{a}}$ of the carboxylic acid although they do not give a specific binding mechanism [34,41-43] and the structural details of the adsorbed bilayer are not reported.

Karaman and Megias-Alguacil observed changes in the contact angle after the adsorption of organic carboxylates on alumina surfaces $[44,45]$. Desset-Brèthes also showed adsorption using UV-vis spectroscopy and recognised the combination of carbon skeleton and strong complexing groups required to produce the highest affinity of the carboxylate ligands onto alumina surfaces at the $\mathrm{pH}$ near their $\mathrm{p} K_{\mathrm{a}}$ values [46]. Other ligands such as phosphate and metal ions also have been reported to adsorb onto hydrous oxide surfaces, and some exhibit a maximum in the adsorption at a $\mathrm{pH}$ near the ligands' $\mathrm{p} K_{\mathrm{a}}$ value $[12,34,47-51]$.

The ligand exchange mechanism has been proposed by several authors in particular cases. Stumm et al. $[33,34]$ noted that organic ligands formed surface complexes with hydrous oxides by ligand exchange and provides the explanation in terms of surface and solution equilibrium constants, highlighting the specific adsorption of ligands and the distinctive $\mathrm{pH}$ behaviour. Goldberg and Sposito [50] reported that the adsorption of phosphate ions on several hydroxylated minerals occurs through a ligand exchange [49,52-57]. They also emphasised a distinctive maximum in adsorption at a particular $\mathrm{pH}$.

The surface of sapphire has been used to study the adsorption of surfactants and polymers from water using neutron reflection [51,58-60]. According to Hellsing et al. [51], there is no significant change in the adsorbed amount or structure of the adsorbed Aerosol-OT (sodium bis(2-ethylhexyl) sulfosuccinate, NaAOT) layer with change in $\mathrm{pH}$ on sapphire, explained that the driving force for the adsorption of NaAOT is self-assembly of the hydrophobic tails. Li et al. [59] showed the gradual decrease in surface excess of sodium dodecyl sulphate (SDS) with the increase of $\mathrm{pH}$ on sapphire surface, which could correspond with the surface charge and be attributed to electrostatic interaction.

\section{Conclusion}

In this work we present adsorption isotherms of sodium hexanoate on $\alpha$-alumina substrates using solution depletion and neutron reflection methods. This adsorption has distinctive $\mathrm{pH}$ dependent behaviour showing a maximum in the adsorption at the $\mathrm{pH}$ near the $\mathrm{p} K_{\mathrm{a}}$ of the hexanoate molecules. This distinctive behaviour indicates that the mechanism of this adsorption may be 'ligand exchange', although other mechanisms cannot be ruled out. The structural nature of the adsorbed layer has been determined and is a bilayer which is essentially completed at the maximum adsorption (at $\mathrm{pH}$ 5) but forms a much more diffuse and imperfect bilayer at $\mathrm{pH} 7$.

\section{Acknowledgments}

We thank BP for financial support for this work, the ISIS staff and scientists (RB 1220199) for the allocation of beam time and technical assistance with NR measurements. We also appreciate Dr. Christopher Richardson at BP Institute, University of Cambridge for helping to write the programme with equilibrium constants.

\section{References}

[1] D. Yang, M. Krasowska, R. Sedev, J. Ralston, Phys. Chem. Chem. Phys. 12 (2010) 13724.

[2] G.V. Franks, L. Meagher, Colloid Surf. A 214 (2003) 99.

[3] D. Zhang, Y. Wang, Y. Gan, Appl. Surf. Sci. 273 (2013) 405.

[4] W.A. Ducker, Z. Xu, D.R. Clarke, J.N. Israelachvili, J. Am. Ceram. Soc. 77 (1994) 437.

[5] J.P. Fitts, X.M. Shang, G.W. Flynn, T.F. Heinz, K.B. Eisenthal, J. Phys. Chem. B 109 (2005) 7981.

[6] R.G. Horn, D.R. Clarke, M.T. Clarkson, J. Mater. Res. 3 (1988) 413.

[7] R.J. Kershner, J.W. Bullard, M.J. Cima, Langmuir 20 (2004) 4101.

[8] I. Larson, C.J. Drummond, D.Y.C. Chan, F. Grieser, Langmuir 13 (1997) 2109.

[9] K. Sue, F. Ouchi, K. Minami, K. Arai, J. Chem. Eng. Data 49 (2004) 1359.

[10] M.J. Rosen, Adsorption of Surface-Active Agents at Interfaces: The Electrical Double Layer, John Wiley \& Sons, Inc., 2004.

[11] R.J. Hunter, Introduction to Modern Colloid Science, Oxford University Press, 1993.

[12] H.B. Bradl, J. Colloid Interface Sci. 277 (2004) 1.

[13] S. Brunauer, The Adsorption of Gases and Vapours, Princeton University Press, Princeton, 1945.

[14] B.-Y. Zhu, T. Gu, Adv. Colloid Interface Sci. 37 (1991) 1.

[15] T. Gu, B.-Y. Zhu, Colloid Surf. 44 (1990) 81.

[16] S.G. Dick, D.W. Fuerstenau, T.W. Healy, J. Colloid Interface Sci. 37 (1971) 595

[17] J.F. Scamehorn, R.S. Schechter, W.H. Wade, J. Colloid Interface Sci. 85 (1982) 463.

[18] J.F. Scamehorn, R.S. Schechter, W.H. Wade, J. Colloid Interface Sci. 85 (1982) 479.

[19] P. Somasund, D.W. Fuersten, J. Phys. Chem. 70 (1966) 90.

[20] C.H. Giles, A.P. Dsilva, I.A. Easton, J. Colloid Interface Sci. 47 (1974) 766.

[21] J. Penfold, R.K. Thomas, J. Phys.: Condens. Matter. 2 (1990) 1369.

[22] T.L. Crowley, E.M. Lee, E.A. Simister, R.K. Thomas, Physica B 173 (1991) 143.

[23] J.R. Lu, E.M. Lee, R.K. Thomas, Acta Crystallogr. Sect. A 52 (1996) 11.

[24] M. Born, E. Wolf, Principle of Optics: Electromagnetic Theory of Propagation, Interference and Diffraction of Light, seventh ed., Pergamon press, Oxford, 1999. pp. 70.

[25] F. Abeles, Ann. de Physique 5 (1950) 706.

[26] J. Webster, S. Holt, R. Dalgliesh, Physica B 2 (2006) 1164. Part 2.

[27] J.R.P. Webster, S. Langridge, R.M. Dalgliesh, T.R. Charlton, Eur. Phys. J. Plus 126 (2011) 112.

[28] A.V. Hughes, RasCAL (2012) <http://sourceforge.net/projects/rscl/>

[29] B. Thalody, G.G. Warr, J. Colloid Interface Sci. 188 (1997) 305.

[30] F. Eriksson, J.C. Eriksson, P. Stenius, Colloid Surf. 3 (1981) 339.

[31] A.K. Bickerstaffe, N.P. Cheah, S.M. Clarke, J.E. Parker, A. Perdigon, L. Messe, A. Inaba, J. Phys. Chem. B 110 (2006) 5570.

[32] D.G. Wiesler, L.A. Feigin, C.F. Majkrzak, J.F. Ankner, T.S. Berzina, V.I. Troitsky, Thin Solid Films 266 (1995) 69.

[33] W. Stumm, J.J. Morgan, Aquatic Chemistry: Chemical Equilibria and Rates in Natural Waters, third ed., John Wiley and Sons Ltd., New York/US, 1995.

[34] R. Kummert, W. Stumm, J. Colloid Interface Sci. 75 (1980) 373.

[35] A.K. Karamalidis, D.A. Dzombak, Surface Complexation Modeling, John Wiley \& Sons, Inc., USA, 2010.

[36] Z.Y. Tao, J.Z. Du, T.W. Chu, React. Funct. Polym. 31 (1996) 17.

[37] C.H. Wu, S.L. Lo, C.F. Lin, Colloid Surf. A 166 (2000) 251.

[38] M.H. Wood, S.M. Clarke, Acta Crystallogr. Sect. E 69 (2013) 0346.

[39] J.E. Del Bene, J. Phys. Chem. 92 (1988) 2874

[40] X. Wang, S.Y. Lee, K. Miller, R. Welbourn, I. Stocker, S. Clarke, M. Casford, P. Gutfreund, M.W.A. Skoda, Langmuir 29 (2013) 5520.

[41] H.L. Yao, H.H. Yeh, Langmuir 12 (1996) 2989.

[42] H.L. Yao, H.H. Yeh, Langmuir 12 (1996) 2981.

[43] P.C. Hidber, T.J. Graule, L.J. Gauckler, J. Am. Ceram. Soc. 79 (1996) 1857

[44] D. Megias-Alguacil, E. Tervoort, C. Cattin, L.J. Gauckler, J. Colloid Interface Sci. 353 (2011) 512.

[45] M.E. Karaman, D.A. Antelmi, R.M. Pashley, Colloid Surf. A 182 (2001) 285

[46] S. Desset-Brèthes, B. Cabane, O. Spalla, J. Phys. Chem. A 116 (2012) 6511.

[47] J.A. Davis, J.O. Leckie, J. Colloid Interface Sci. 74 (1980) 32

[48] L. Sigg, W. Stumm, Colloid Surf. 2 (1981) 101.

[49] F.J. Hingston, R.J. Atkinson, A.M. Posner, J.P. Quirk, Nature 215 (1967) 1459

[50] S. Goldberg, G. Sposito, Commun. Soil Sci. Plan. 16 (1985) 801.

[51] M.S. Hellsing, A.R. Rennie, A.V. Hughes, Langmuir 26 (2010) 14567.

[52] A. Breeuwsm, J. Lyklema, J. Colloid Interface Sci. 43 (1973) 437.

[53] F.J. Hingston, A.M. Posner, J.P. Quirk, J. Soil Sci. 25 (1974) 16.

[54] F.J. Hingston, J.P. Quirk, A.M. Posner, J. Soil Sci. 23 (1972) 177.

[55] R.L. Parfitt, J.D. Russell, V.C. Farmer, J. Chem. Soc. Faraday Trans. I 72 (1976) 1082.

[56] S.S.S. Rajan, K.W. Perrott, W.M.H. Saunders, J. Soil Sci. 25 (1974) 438

[57] J.D. Russell, R.L. Parfitt, A.R. Fraser, V.C. Farmer, Nature 248 (1974) 220

[58] M.S. Hellsing, A.R. Rennie, A.V. Hughes, Langmuir 27 (2011) 4669.

[59] N. Li, R.K. Thomas, A.R. Rennie, J. Colloid Interface Sci. 378 (2012) 152.

[60] N. Li, R.K. Thomas, A.R. Rennie, J. Colloid Interface Sci. 369 (2012) 287. 